\title{
Effect of Acid Concentration on the Extraction of Furfural from Corn Cobs
}

\author{
Amir Shafeeq, Ayyaz Muhammad, Shahid Sarfaraz, Ziad Akram, H. M. Usman Saeed, and Umar \\ Farooq
}

\begin{abstract}
Furfural was prepared from corn cobs available locally in this study. The process consisted of crushed corn cobs, sulfuric acid and salt mixture. The mixture was heated to about $120^{\circ} \mathrm{C}$ for about 2 hours to extract furfural water solution from the mixture. From the furfural water system, furfural was extracted by using ether. Ether extracted furfural from the furfural water system. As ether has low boiling point so furfural could be recovered from ether by simply heating the solution to about $33^{\circ} \mathrm{C}$. Results suggest that percentage yield of furfural could be increased by increasing the concentration of sulfuric acid.
\end{abstract}

Index Terms - Corn cobs, extraction, furfural.

\section{INTRODUCTION}

Furfural was first discovered in 1821 by a German scientist Dobereiner. Emmett in 1832 observed that most vegetable substances could be a source of furfural.

Stenhous in 1840 made the empirical formula, $\mathrm{C}_{5} \mathrm{H}_{4} \mathrm{O}_{2}$ of furfural and found the resin-forming tendency of furfural. The boiling point was found to be $168^{\circ} \mathrm{C}$ and specific gravity $1.100^{\circ} 66$ at $27^{\circ} \mathrm{C}$.

Later on, Stenhous discovered the nature of vegetative materials that could be a source of furfural after treatment with sulphuric acid. German Chemist Carl Harries suggested furfural's structure.

However, use of furfural remained scarse until 1922, then the Quaker Oats Company started mass-production of oat hulls from it.

Today, production of furfural is done by agricultural byproducts like sugarcane bagasse and corn cobs. The Dominican Republic, South Africa and China are the main countries producing furfural today.

A number of plants have the polysaccharide hemicellulose which is a polymer of sugar along with five carbon atoms. On reaction with sulfuric acid, this hemicellulose hydrolysis to produce xylose.

In the presence of same operating environment of heat and acid, xylose along with other five carbon sugars dehydrate and release three water molecules to produce furfural:

$$
\mathrm{C}_{5} \mathrm{H}_{10} \mathrm{O}_{5} \rightarrow \mathrm{C}_{5} \mathrm{H}_{4} \mathrm{O}_{2}+3 \mathrm{H}_{2} \mathrm{O}
$$

Crop residue feedstocks is another source of furfural. About $3 \%$ to $10 \%$ of the mass of the plant could be recovered

Manuscript received September 30, 2014; revised December 29, 2014.

The authors are with the Institute of Chemical Engineering and Technology, University of the Punjab, Lahore (e-mail: amir_engr@yahoo.com). to produce furfural. However, it depends upon the type of feedstock. Furfural along with water evaporate forming the reaction mixture. The separation could be done using condensation.

Furfural also known as (2-furfural aldehydes, furfural, 2-Furan Carboxaldehyde, furfuraldehyde, fural) is the principal member of five membered heterocyclic compounds called "furans" which are characterized by an unsaturated ring of four carbon atom and one oxygen atom. Its chemical formula is OC4H3CHO: [1]-[3].

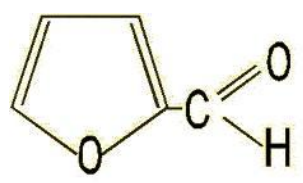

Furfural behavior in chemical reactions is similar to other aldehydes and aromatics. This shows its diminished aromaticity with regards to benzene. Furfural can be easily hydrogenated to the corresponding tetrahydrofuran derivatives.

If heated above $250{ }^{\circ} \mathrm{C}$, furfural gives furan and carbon monoxide. However, it behaves explosively sometimes if heated in the presence of acids.

Furfural is a chemical feedstock and has properties of being renewable and non-petroleum based. Furfural on hydrogenation gives furfuryl alcohol (FA).

FA is proved to be a very important chemical intermediate. It is further hydrogenated to produce tetrahydrofurfuryl alcohol (THFA).

THFA is being employed to be a nonhazardous solvent for various agricultural formulations. It is used to help herbicides in penetrating the leaf structure.

Furfural is also used to produce various furan chemicals, such as furoic acid, and furan. This is done by palladium catalyzed vapor phase decarbonylation.

The residue produced after the removal of furfural is lignocellulosic which could be used for the generations of steam which is used in the furfural plant.

This could further be used for the co-generation of electricity, cattle feed, activated carbon and fertilizer. It is being used widely as glue extender in the industry of North American board.

The natural sources of Furfural are Rice Husk, Corn Cobs and Bagasse. Yield of Furfural on Selected Raw Material on the basis of \% weight of Raw Material per day is given in Table I.

\section{A. Rice Husk}

Paddy consists of $30 \%$ husk and $70 \%$ rice. 5 tons per day 
furfural requires 80-tons/day rice husk, which corresponds to 270-tons/day, and 190 tons per day rice. In Pakistan, Rice husk is available at Rs. 70-90 per ton, depending upon the location of the source.

Most of the Mills are willing to provide free of charge, but considering the low depravity of material, the transportation and storage cost cover a large portion of the delivered price. An ideal arrangement should be to locate the plant next to the rice mill.

\section{B. Corn Cobs}

The yield of furfural from corncob is the highest and this makes corncob a desirable raw material. Corncob is the central part of maize. It is the ear part on which the kernels are grown. The ear of corn plant can also be taken as a "cob".

Baby corn can be used as the raw material. However, as the plant grows, the cob turns to be more tough and then only the kernels can be edible.

During the harvesting of corn, the corncob could be collected as part of the ear. However, it could be left as part of the corn stover. The innerside of the cob is white and looks similar to foam plastic.

\section{Bagasse}

Bagasse is used as fuel in sugar mills, and in some cases for the manufacture of paper and hard board. As sugar cane production in Pakistan is large so bagasse is available in abundant quantity.

Moreover, the availability of bagasse as a raw material for the production of furfural can be increased by using gas fired boiler in sugar mills.

The storage of bagasse is difficult and expensive so furfural unit should be located near a sugar mill. Five-tons/day furfural production requires 30-tons/day bagasse, which is available from 200-tons/day sugar cane.

There are about 70 sugar mills in Pakistan and in almost all of these mills, bagasse is used as boiler fuel. Using the bagasse as a raw material for the production of furfural could be very attractive as furfural is a high cost organic chemical.

TABLE I: PENTOSANS CONTENT AND FURFURAL YIELD IN DIFFERENT RAW MATERIALS

\begin{tabular}{lll}
\hline \hline Raw Material & Pentosans content & $\begin{array}{l}\text { Furfural yield in } \\
\text { Industrial operation }\end{array}$ \\
\hline Corn Cobs & $30-32$ & 10 \\
\hline Rice Husk & $16-18$ & 6 \\
\hline Bagasse & $25-27$ & $8-9$ \\
\hline Cotton Husk & 27 & $8-9$ \\
\hline Oat Husk & Minimum 32 & 10 \\
\hline Almond Husk & Minimum 30 & $9-10$ \\
\hline Olive press cake & $21-23$ & $5-6$ \\
\hline \hline
\end{tabular}

The conventional processes for the production of furfural include:

Agrifurnace Process. Super phosphate, phosphoric acid as a catalyst is used.

\section{1) Quaker Oats process}

Sulphuric acid is used as a catalyst.

\section{2) SAVO process}

It does not require a separate catalyst.

In all these processes, reaction takes place at elevated pressures and involves digestion using superheated steam. As a result, furfural flashes out from the reactor with steam.

The mixture of furfural and steam is condensed to produce dilute solution from which furfural may be recovered by fractional or vacuum distillation.

The savo process is the simplest of all and need less maintenance and has trouble free operation characteristics. The raw materials used in the preparation of furfural could be Non Pentosans or Pentosans [4]-[6].

Cellulose and polyuronic acids could be converted to furfural under suitable conditions. These are non pentosans materials. In the case of cellulose, the conversion to furfural takes place via glucuronic acid.

Pectin which is now regarded as poly uronic acid could also produce furfural under similar conditions. The uronic acid is readily decarboxylated on boiling and pentose, xylon or arabinose is formed.

Another material that can be converted into furfural is ascorbic acid boiled with hydrochloric ascorbic acid and gives a quantitative determination of furfural. The conversion of pentosans to furfural takes place in two steps.

1) Hydrolysis of Pentosans to Pentoses: Pentosans in hemicelluloses is hydrolyzed with dilute mineral acids at relatively low temperature to pentosans liquor. A major $75 \%$ of these pentosans is readily hydrolysable to pentoses.

2) Conversion of Pentosans to Furfural: The formation of furfural from pentoses is an ordinary process of dehydration with the elimination of three molecules of water.

Furfural has rather high order of stability towards heat in the absence of catalyst and oxygen. The initial decomposition temperature has been found to be $565^{\circ} \mathrm{C}$ for a contact period of 20 seconds.

In commercial terms, the most important intermediary derived from furfural is furfural alcohol (FA).

This Furfural alcohol primarily used to make furan resins, but it may also be converted into tetra hydro furfuryl alcohol (THFA) [7], [8].

\section{MATERIALS AND MethodS}

The following steps are involved for the production of furfural at laboratory scale:

1) Pressurized cooking of raw material with dilute acid

2) Condensation of cooker vapors

3) Azeotropic distillation of furfural

4) Condensation of two layers and decantation of water layers

5) Drying of furfural

6) Coloring and filtrationApparatus:

Reaction Flask, Long Glass Tube, Condenser, Collecting Flask, Heating media

\section{A. Raw Materials}

Salts, Corncobs, $\mathrm{H}_{2} \mathrm{SO}_{4}$, Ether, Water

\section{B. Procedure}

Corn cobs (+40 mesh size), $\mathrm{H}_{2} \mathrm{SO}_{4} \&$ Salt were added into the reaction flask. Reaction flask was connected to long 
vertical tube so as to provide sufficient length for vapors of Furfural.

This long tube was then connected to the condenser in which cold water is flowing to condense the vapors of Furfural.

The vapors of furfural were then collected in a collecting flask. Heating media used was an electric heater and the temperature was set at $120 \mathrm{C}$.

For all the samples, the weight (Corn cobs) to volume $\left(\mathrm{H}_{2} \mathrm{SO}_{4}\right)$ ratio was set to be 1:5. Volume of the solution was set to be $750 \mathrm{ml}$. The time of heating was fixed at $125 \mathrm{~min}$.

\section{Extraction}

Furfural could be extracted from water using solvent extraction method employing ether as a solvent. After extraction the upper layer would contain furfural and ether and the lower layer would contain water. Furfural could be separated from the upper layer by evaporating ether.

\section{RESULTS AND DISCUSSIONS}

Four Samples with different concentration of acid were prepared.

Sample 1:

Weight of corn cobs $=150 \mathrm{~g}$,

Percentage of $\mathrm{H}_{2} \mathrm{SO}_{4}=5 \%$,

Volume of $\mathrm{H}_{2} \mathrm{SO}_{4}=38 \mathrm{ml}$,

Volume of water $=712 \mathrm{ml}$

Salt taken $=150 \mathrm{~g}$,

Total sample collected $=120 \mathrm{ml}$

Addition of Ether $=120 \mathrm{ml}$,

Upper layer $=78 \mathrm{ml}$, Lower layer $=162 \mathrm{ml}$

After evaporation the weight of furfural obtained $=2.3 \%$.

Sample 2:

Weight of corn cobs $=150 \mathrm{~g}$,

Percentage of $\mathrm{H}_{2} \mathrm{SO}_{4}=10 \%$,

Volume of $\mathrm{H}_{2} \mathrm{SO}_{4}=77 \mathrm{ml}$,

Volume of water $=673 \mathrm{ml}$

Salt taken $=150 \mathrm{~g}$,

Total sample collected $=150 \mathrm{ml}$

Addition of Ether $=120 \mathrm{ml}$,

Upper layer $=110 \mathrm{ml}$, Lower layer $=160 \mathrm{ml}$

After evaporation the weight of furfural obtained $=4.6 \%$

Sample 3:

Weight of corn cobs $=150 \mathrm{~g}$,

Percentage of $\mathrm{H}_{2} \mathrm{SO}_{4}=15 \%$,

Volume of $\mathrm{H}_{2} \mathrm{SO}_{4}=115 \mathrm{ml}$,

Volume of water $=635 \mathrm{ml}$

Salt taken $=150 \mathrm{~g}$,

Total sample collected $=210 \mathrm{ml}$,

Addition of Ether $=120 \mathrm{ml}$,

Upper layer $=130 \mathrm{ml}$, Lower layer $=200 \mathrm{ml}$,

After evaporation the weight of furfural obtained $=7.6 \%$

Sample 4:

Weight of corn cobs $=150 \mathrm{~g}$,

Percentage of $\mathrm{H}_{2} \mathrm{SO}_{4}=20 \%$,

Volume of $\mathrm{H}_{2} \mathrm{SO}_{4}=153 \mathrm{ml}$,

Volume of water $=597 \mathrm{ml}$

Salt taken $=150 \mathrm{~g}$,

Total sample collected $=425 \mathrm{ml}$
Addition of Ether $=120 \mathrm{ml}$,

Upper layer $=190 \mathrm{ml}$, Lower layer $=355 \mathrm{ml}$

After evaporation the weight of furfural obtained $=8.3 \%$

The following two tests for the confirmation of the sample of furfural were performed

\section{A. Molisch's Test}

Molisch's test is named after the name of Austrian botanist Hans Molisch. This test is used to confirm the presence of carbohydrates. This results from the dehydration of the carbohydrate in the presence of sulfuric acid or hydrochloric acid to produce an aldehyde. This further condenses to two molecules of phenol which is usually red- or purple in colour

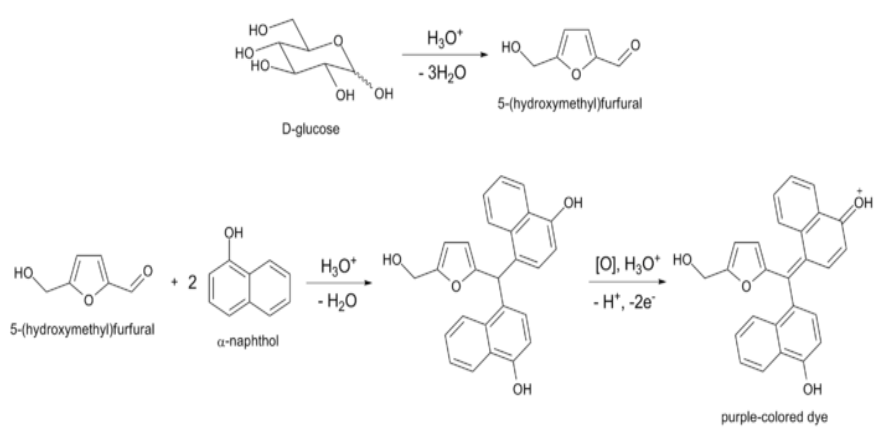

\section{B. Bial's Test}

Bial's test is a chemical test to find the occurrence of pentoses. It's name is after the name of Manfred Bial, a German Physician. It includes orcinol, hydrochloric acid, and ferric chloride. If pentose is present, it will be converted to furfural which further reacts with the orcinol to produce a bluish colored precipitate[9], [10].

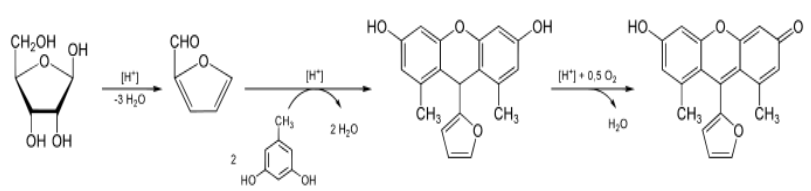

The results so obtained are shown in the Table II and Fig. 1.

TABLE II: ACID CONCENTRATION AND FURFURAL YIELD FOR DIFFERENT SAMPLES

\begin{tabular}{llll}
\hline \hline Sample No. & $\begin{array}{c}\text { Acid Conc. } \\
\%\end{array}$ & $\begin{array}{c}\text { Furfural Yield } \\
\%\end{array}$ \\
\hline 1 & 5 & & 2.3 \\
\hline 2 & 10 & 4.6 & \\
\hline 3 & 15 & 7.6 & \\
\hline 4 & 20 & 8.3 & \\
\hline \hline
\end{tabular}

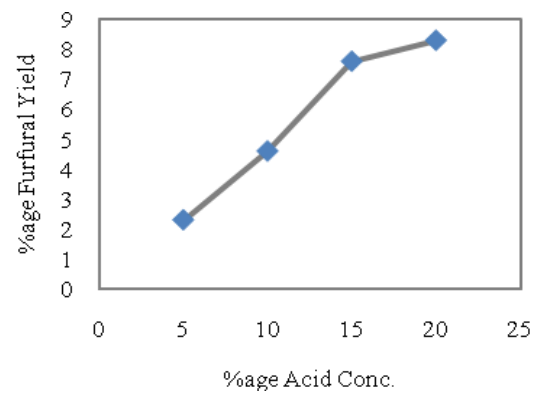

Fig. 1. Acid conc. vs furfural yield. 


\section{CONCLUSION}

Furfural yield increases rapidly with increase in the concentration of acid up to $15 \%$. However, when acid concentration is increased to $20 \%$, the yield slightly decreases because at this concentration of acid, it becomes very difficult to isolate furfural produced in liquid phase by the standard method of laboratory separation i.e. solvent extraction using ether.

The factors upon which the yield of furfural depends are Acid/Solid (volume to weight Ratio), Temperature, Time of digestion and Pressure.

\section{REFERENCES}

[1] N. Kaliyan and R. Vance Morey, "Densification characteristics of corn cobs," Fuel Processing Technology, vol. 91, no. 5, pp. 559-565, 2010.

[2] W. T. Tsai, C. Y. Chang, S. Y. Wang, C. F. Chang, S. F. Chien, and H. F. Sun, "Cleaner production of carbon adsorbents by utilizing agricultural waste corn cob," Resources, Conservation and Recycling, vol. 32, no. 1, pp. 43-53, 2001.

[3] C. A. Mullen, A. A. Boateng, N. M. oldberg, I. M. Lima, D. A. Laird, and K. B. Hicks, "Bio-oil and bio-char production from corn cobs and stover by fast pyrolysis," Biomass and Bioenergy, vol. 34, no. 1, pp. 67-74,2010.

[4] W. R. Fernell and H. K. King, "The simultaneous determination of pentose and hexose in mixtures of sugars," Analyst, vol. 78, pp. 80-83, 1953.

[5] H. L. Li, A. J. Deng, J. L. Ren, C. Y. Liu, Q. Lu, L. J. Zhong, F. Peng, and R. C. Sun, "Catalytic hydrothermal pretreatment of corncob into xylose and furfural via solid acid catalyst," Bioresource Technology, vol. 158, pp. 313-320, 2014.
[6] S. J. Oh, S. H. Jung, and J. S. Kim, "Co-production of furfural and acetic acid from corncob using $\mathrm{ZnCl} 2$ through fast pyrolysis in a fluidized bed reactor," Bioresource Technology, vol. 144, pp. 172-178, 2013.

[7] H. L. Li, J. L. Ren, L. J. Zhong, R. C. Sun, and L. Liang, "Production of furfural from xylose, water-insoluble hemicelluloses and water-soluble fraction of corncob via a tin-loaded montmorillonite solid acid catalyst," Bioresource Technology, vol. 176, pp. 242-248, 2015.

[8] I. A. Telleria, I. Gandarias, and P. L. Arias, "Production of furfural from pentosan-rich biomass: Analysis of process parameters during simultaneous furfural stripping," Bioresource Technology, vol. 143, pp. 258-264, 2013

[9] A. Avci, B. C. Saha, G. J. Kennedy, and M. A. Cotta, "industrial crops and products high temperature dilute phosphoric acid pretreatment of corn stover for furfural and ethanol production," vol. 50, pp. 478-484, 2013

[10] A. Chareonlimkun, V. Champreda, A. Shotipruk, and N. Laosiripojana, "Catalytic conversion of sugarcane bagasse, rice husk and corncob in the presence of $\mathrm{TiO}_{2}, \mathrm{ZrO}_{2}$ and mixed-oxide $\mathrm{TiO}_{2}-\mathrm{ZrO}_{2}$ under hot compressed water (HCW) condition," Bioresource Technology, vol. 101, no. 11, pp. 4179-4186, 2010.

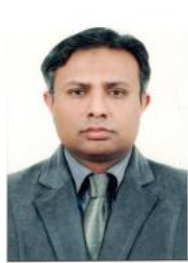

Amir Shafeeq has B.Sc. M.Sc. and PhD degrees in chemical engineering and master degree in business administration. He is an associate professor in Institute of Chemical Engineering \& Technology, University of the Punjab, Lahore, Pakistan. He is supervising various research projects in chemical engineering \& project management. His areas of interest include process integration and intensification, simulation and modeling of batch processes, separation processes, fluid and particle mechanics, industrial management and process economics. 